\title{
Por amor e por direitos: as gramáticas do afeto e da política nas mobilizações públicas de familiares de autistas
}

FERNANDA NunES

Universidade Federal do Rio de Janeiro, Rio de Janeiro, Rio de Janeiro, Brasil

DOI 10.11606/issn.2316-9133.v25i25p222-245

resumo O período entre 2009 e 2012 foi considerado um marco na história das pessoas com autismo no Brasil devido à sanção da lei federal no 12.764/2012, que reconheceu os autistas, para todos os efeitos legais, como pessoas com deficiência. A legislação é fruto do reconhecimento público de manifestações de pais e familiares, em um contexto de positivação do termo deficiência como instrumento político-identitário da "luta por direitos". Este trabalho aborda as principais estratégias de visibilidade adotadas por movimentos de familiares de autistas no estado do Rio de Janeiro. Pretende-se responder, assim, aos seguintes quesitos: a) Quais processos e motivações permitem que uma questão privada se transforme em uma questão pública? b) Quais são os artifícios utilizados em nome de demandas "pró-autistas" e de que forma eles atuam na construção de políticas públicas voltadas ao segmento? A metodologia envolveu entrevistas com informantes qualificados e observação participante em eventos públicos, mobilizações e passeatas organizados por três grupos de pais de autistas.

palavras-chave Atuação política; Autismo; Deficiência; Direitos; Saúde.

For love and for rights: the grammars of affection and politics in the public mobilizations of autistic relatives

abstract The period between 2009 and 2012 was considered a landmark in the history of autistic people in Brazil, due to the enactment of the Federal Law 12.764/2012, which recognized autistics such as people with disabilities, for all legal purposes. This legislation is a result of public recognition of expressions of parents and relatives, in a context of disability positivation term as a political identity instrument of "right struggles". This paper approaches the main visibilities strategies adopted by movements of autistic parents in the state of Rio de Janeiro. The objective is answer the following questions: a) What processes and motivations allow a private matter (having an autistic child) become a public 
issue? b) What are the devices used for "pro-autistic" demands and how do they work for the construction of public policies? In addition to interviews with qualified informants, the research methodology involved participant observation in demonstrations, public hearings and lectures organized by these groups.

keywords Political action; Autism; Disability; Rights; Health.

\section{Introdução}

Este artigo abordará as estratégias de visibilidade performatizadas por grupos de familiares de autistas no estado do Rio de Janeiro, entre 2012 e 2013, na "luta por direitos". Esse período foi considerado um marco na história das pessoas com autismo no Brasil devido à sanção da lei federal no 12.764/2012, que reconheceu os autistas, para todos os efeitos legais, como pessoas com deficiência. Reflexo dos chamados "novos" movimentos sociais ${ }^{1}$ no país, as reivindicações por direitos dos autistas tiveram pais e familiares como principais interlocutores.

Como alternativa aos modelos classificatórios biomédicos, ${ }^{2}$ as experiências do autismo serão apresentadas a partir de categorias êmicas. Assim, os termos "autismo clássico" ou "moderado" aparecerão entre aspas ao longo do texto. De acordo com os entrevistados, essas categorias remetem ao nível de dificuldades na tríade interação, socialização e comunicação.

A abordagem metodológica da pesquisa envolveu entrevistas em profundidade, gravadas em formato de áudio, com nove familiares de autistas que assumem a condição de participantes e/ou fundadores de associações ou grupos. Neste artigo, optei por não revelar os nomes verídicos das instituições pesquisadas. Serão designadas, então, por grupo Azul Claro, grupo Azul Celeste e grupo Azul Marinho. ${ }^{3}$

No momento da pesquisa, esses eram os três grupos de maior atuação políti-

\footnotetext{
${ }^{1}$ Os chamados "novos" movimentos sociais, surgidos entre as décadas de 1960 e 1970, vêm recebendo destaque na literatura nacional e internacional como modelo anglo-saxão de reivindicação política de direitos civis por grupos historicamente estigmatizados, tais como os movimentos negro, feminista, LGBT e de pessoas com deficiência e doenças diversas. De acordo com a literatura sobre o tema, o que os define como "novos" é o deslocamento das premissas relacionadas às desigualdades socioeconômicas da população para a ênfase no direito à diferença e nas questões identitárias e culturais (EPSTEIN, 1996; BROWN; ZAVESTOSKI, 2004; GOHN, 1997; 2010; ALONSO, 2009; GOLDMAN, 2007).

2 Atualmente, o autismo é diagnosticado por meio de definições biomédicas de sistemas classificatórios, como o Diagnostic and Statistical Manual of Mental Disorders (APA, 2013) que se encontra em sua quinta edição.

${ }^{3} \mathrm{O}$ azul é a cor-símbolo do autismo, em referência à maior prevalência da deficiência entre o sexo masculino. Dados do Center for Diseases Control and Prevention (CDC) indicam que a incidência de casos de autismo é 1:88 (cerca de 11 casos para 1.000 crianças), sendo mais frequente entre pessoas do sexo masculino (1:54) do que entre as do sexo feminino (1:252) (CDC, 2012).
} 
ca no estado do Rio de Janeiro. Juntos ou de forma independente, participaram de audiências públicas em Brasília e no Rio de Janeiro, mobilizaram-se no envio de e-mails para autoridades, organizaram-se em grupos virtuais na internet com a finalidade de debater novas estratégias de visibilidade, bem como realizaram manifestações, vestidos de azul, com faixas e cartazes nas mãos, pleiteando a aprovação da chamada "Lei do autista" (lei federal no 12.764/2012).

Ao longo de um ano, a metodologia de pesquisa também incluiu observação participante em eventos públicos de caráter mobilizador organizados pelos grupos de pais (passeatas, audiências públicas, palestras e celebrações de datas comemorativas, como o Dia Mundial da Conscientização do Autismo). A maior parte do trabalho etnográfico se desenvolveu no município de Volta Redonda, onde está localizado grupo Azul Claro. Após idas quinzenais à cidade, passei a ser diretamente convidada a participar dos eventos realizados pela associação, sem que houvesse a necessidade de pedir autorização para estar presente. Não raro, os participantes do grupo Azul Claro se dispunham a oferecer carona até a rodoviária, momento no qual, quase sempre, eram revelados pensamentos indizíveis diante do gravador ligado, tais como as divergências entre membros do grupo. Alguns familiares também passaram a se referir a mim como "amiga dos autistas", rendendo, inclusive, um agradecimento público na fanpage do grupo, no Facebook, após minha participação como voluntária na feijoada beneficente, ocorrida em julho de 2013.

A constante presença em campo também consolidou formas variadas de interação entre mim e os autistas que frequentavam a sede e eventos promovidos pelo Azul Claro. Em um momento inicial, apenas dirigia-me a eles - em sua maioria adultos, pouco ou não verbais - com um breve cumprimento: "oi, tudo bem, [nome da pessoa]?”. Em alguns casos, a resposta vinha sob a forma de ecolalia; ${ }^{4}$ em outros, como silêncio.

Novas interações, explicitamente afetuosas, se estabeleceram com o passar do tempo. Após o trabalho como voluntária da feijoada beneficente que pretendia arrecadar fundos para o Azul Claro, Romulo, autista adulto, espontaneamente se despediu de mim com um beijo no rosto. Para mim, aquele foi um momento de surpresa e emoção, visto que o jovem raramente respondia, quando me dirigia a ele com uma saudação. Já outra autista adulta - Bruna, de 38 anos -, que recusava o contato físico com "pessoas de fora", passou a me dar a mão e a falar frases curtas.

$\mathrm{Na}$ seção seguinte, apresentarei algumas das características e linhas de atuação de cada coletivo, a fim de refletir, ao longo do texto, sobre quais processos e motivações permitem a politização do fenômeno. Antecipo que, de modo geral, as propostas centrais dos grupos analisados priorizam "conscientização da sociedade", "luta por direitos" e acesso a serviços "específicos" e "especializados" em autismo.

${ }^{4}$ Comum entre autistas, a ecolalia é a repetição de frases ou palavras ouvidas. 


\section{Sobre grupos, demandas e alegações: atuações globais e locais}

O grupo Azul Claro é considerado pioneiro nas ações voltadas para autistas no estado do Rio de Janeiro. Localizado em Volta Redonda, município do sul fluminense, foi fundado em 1999, exclusivamente por familiares de autistas e, hoje, é referência para outros grupos e associações do estado. O município é tido, ainda, como paradigmático por ser o primeiro, no Brasil, a sancionar três leis municipais referentes ao autismo, que dispõem sobre: a instituição do Dia Municipal de Conscientização do Autismo; o reconhecimento do autista como pessoa com deficiência e a implantação de um centro de atendimento integral para pessoas com transtorno do espectro autista no município.

O trabalho do Azul Claro, entretanto, não se dá apenas no campo das demandas e reivindicações políticas. Em sua sede, a instituição oferece cursos, atividades pedagógicas e palestras que se dividem em "grupo das mães", "grupo dos pais", "grupo da família" e "grupo de familiares de autistas adultos". Ministradas por profissionais das áreas de educação, direito e saúde, essas palestras recebem destaque pelo protagonismo dos associados, os quais podem compartilhar experiências, sugerir atividades e limar dúvidas. Os encontros mensais foram acompanhados por mim como forma de apreender que tipo de informação vem sendo compartilhada e como interagem pais, familiares, autistas e profissionais nesses espaços.

Com estatuto próprio e cargos definidos (presidência, vice-presidência, secretaria, tesouraria, diretoria social e conselho fiscal), até 2013 o grupo Azul Claro teve três presidentes, todas mulheres, sendo duas mães e uma irmã de autistas, eleitas por meio de votação dos associados, bianualmente. No período da pesquisa, cerca de 150 famílias pagavam uma mensalidade simbólica de R \$ 5,00 (cinco reais), porém, a instituição era mantida, majoritariamente, com o dinheiro arrecado em festas, eventos, rifas e por meio de doações.

O caráter misto de filantropia e luta política está vinculado, sobretudo, à forma como se concebe o autismo na associação. A prática do "acolhimento" (termo nativo) envolve o preenchimento de uma ficha por todas as famílias, na qual declaram, entre outras características, o tipo de atividade profissional que exercem e a situação financeira na qual se encontram. Esse procedimento teve início na gestão de Suzana, ex-presidente do grupo e mãe de um autista adulto "clássico”. Além de mapear o perfil dos que chegam ao local, o cadastramento localiza as necessidades assistenciais mais urgentes, como falta de moradia adequada, condições nutricionais precárias e ausência de saneamento básico. Nesse procedimento, o foco de atenção é a família do autista. A estratégia de "acolhimento" inclui a distribuição de cestas básicas embaladas pelos próprios associados para as famílias cadastradas, uma vez ao mês.

Se no contexto mais amplo da política e da jurisdição o autismo é tratado como deficiência, no campo das atividades locais do Azul Claro, o autismo é concebido também como algo espiritual. Suzana sintetiza: 
Eu não consigo enxergar o autismo só do lado clínico, eu não consigo enxergar o autismo só pela professora que eu sou e as necessidades dele, eu não consigo enxergar o autismo sem ver a parte espiritual, porque eu acho que tudo o que define a gente é espiritual.

A concepção de Suzana foi corroborada por Carla, membro do grupo e também mãe de um autista adulto:

A gente sabe que [o autismo] é uma síndrome. É uma deficiência hoje, é uma deficiência neurobiológica, mas, para mim, é uma forma diferente de ser. É um ser diferente. Nós somos todos diferentes, mas a diferença do autismo tem um sentido, para mim, espiritual, mágico. $\mathrm{O}$ autismo para mim, hoje, é uma forma, é um jeito diferente de estar dentro de um contexto social e ele tem que ser respeitado por isso.

Apesar de ambas seguirem a doutrina espírita, é importante lembrar, no entanto, que a associação não está diretamente vinculada a qualquer tipo de instituição religiosa, como no caso da "comunidade surda" brasileira. ${ }^{5} \mathrm{Na}$ arena política, o trabalho desenvolvido pelo grupo Azul Claro contempla os autistas adultos em suas demandas, sob a previsão de que as crianças recentemente diagnosticadas não tenham "o mesmo destino de exclusão e de invisibilidade dos adultos", conforme destacou uma de minhas informantes.

A maioria desses autistas adultos, filhos ou parentes das pessoas entrevistadas, apresentou dificuldades quanto à recusa da matrícula por escolas regulares, ${ }^{6}$ tendo, assim, estudado em escolas especializadas ("especiais") e convivido a maior parte da vida sob os cuidados dos familiares (em sua maioria, mães e irmãs), sem acesso a lazer, participação na sociedade e tratamentos adequados. $\mathrm{Na}$ relação com seus familiares, dependem de atenção integral com higiene, alimentação e medicação. Dentre os cinco autistas adultos que participaram da

\footnotetext{
${ }^{5} \mathrm{O}$ movimento social formado por pessoas surdas possui uma histórica trajetória de luta pelo reconhecimento jurídico da língua brasileira dos sinais (libras) como particularidade étnico-linguística. O movimento é liderado politicamente pela Federação Nacional de Educação e Integração dos Surdos (Feneis), com a colaboração de intelectuais e agentes religiosos da Igreja Católica e Testemunhas de Jeová (ASSIS SILVA, 2012). Observa-se, porém, que, assim como no caso do autismo, não é possível singularizar o movimento dos surdos. Ele não é unidirecional, uma vez que há surdos que não se identificam com a "cultura surda", tampouco utilizam a "língua dos sinais", mas fazem parte da militância pelos direitos das pessoas com deficiência.

${ }^{6} \mathrm{O}$ sistema educacional inclusivo é assegurado pela Convenção sobre os Direitos das Pessoas com Deficiência da ONU, ratificada no Brasil com status de emenda constitucional pelos decretos no. 186/2008 e no. 6.949/2009. Assim, a Política Nacional de Educação Especial na Perspectiva da Educação Inclusiva (BRASIL, 2008) garante que os alunos com as mais diversas deficiências estejam incluídos em classes regulares, em escolas das redes pública e particular.
} 
pesquisa, todos vivem com pais e/ou irmãos e apenas um deles trabalha formalmente, na prefeitura de uma cidade vizinha. De modo geral, possuem limitações cognitivas e comunicacionais severas. Alguns deles apresentam comorbidades associadas à deficiência, como distúrbio do sono (ausência de sono), hipoatividade (excesso de prostração) e epilepsia. Os familiares também relataram casos de crises nervosas, desencadeadas por mudança repentina de rotina, além de comportamentos auto e heteroagressivos, ainda que essas caraterísticas não sejam regra.

Famílias mais abastadas proporcionam o atendimento semanal a seus filhos, autistas adultos, em clínicas particulares de Volta Redonda, enquanto as demais, com poucas condições financeiras, contam com o tratamento disponível na rede pública de saúde mental, como os Centros de Atenção Psicossocial (CAPS) e os Centros de Atenção Psicossocial Infantojuvenil (CAPSi), ${ }^{7}$ considerado insuficiente e inadequado (NUNES; ORTEGA, no prelo). Antecipando a certeza da vida finita, mães e pais, já idosos, reivindicam a construção de residências assistidas voltadas para autistas adultos. Uma das maiores preocupações é o destino do filho, "inevitavelmente dependente" (KITTAY, 2011), após o falecimento de seus entes mais próximos. Diante das dificuldades enfrentadas por familiares de autistas adultos, o foco nesta população, portanto, assume diferença de estratégias políticas entre os grupos estudados.

Formado em 2005, o grupo Azul Celeste difere do Azul Claro tanto com relação ao perfil socioeconômico dos membros-fundadores quanto ao leitmotiv que marca o início de sua construção como movimento social. Seus oito fundadores são profissionais liberais, pais de autistas ainda em fase escolar, sendo parte deles moradora de um bairro de classe média-alta da cidade do Rio de Janeiro. Seus filhos têm acesso às redes privadas de ensino e de saúde.

O grupo não possui sede fixa e não mantém nenhum tipo de programa de atendimento a pessoas com autismo. Utilizando-se do slogan "O Brasil precisa conhecer o autismo”, nasceu com a intenção de consolidar estratégias de visi-

\footnotetext{
${ }^{7}$ No Brasil, a Reforma Psiquiátrica, iniciada na década de 1980, se endereçou à reformulação da política de assistência à saúde mental, até então centrada no modelo asilar e hospitalocêntrico de atendimento àqueles considerados "loucos". Este período foi consolidado pela ativa participação de movimentos formados por profissionais da saúde, familiares e pacientes. Sem precedentes no Brasil, a lei no 10.216/2001 determinou em parágrafo único os direitos das pessoas com transtornos mentais e previu o desenvolvimento de uma política de saúde mental pelo Estado, bem como a necessidade de alocação de recursos públicos voltados para dispositivos não manicomiais de atendimento (Centros de Atenção Psicossociais I, II, III, CAPSi e AD) e a obrigatoriedade da comunicação das internações compulsórias à autoridade judiciária (BRASIL, 2001; MUSSE, 2008). Logo, de acordo com esse protocolo, os autistas - considerados "pessoas com transtorno mental", para o campo da saúde mental - devem ser encaminhados para atendimento multidisciplinar nos Centros de Atenção Psicossocial (CAPS) e Centros de Atenção Psicossocial Infantojuvenil (CAPSi). Ao longo da pesquisa, contudo, demonstrou-se insatisfação quanto aos serviços, no estado do Rio de Janeiro (NUNES, 2014).
} 
bilidade e de reconhecimento do autismo no país, sob o argumento de que o espectro autista ainda não é conhecido pela sociedade em geral, o que dificulta o diagnóstico precoce (antes dos três anos de idade, mesmo que não definitivo) e, por conseguinte, a estimulação adequada da criança. Segundo informantes, a partir de intervenções precoces, é possível obter avanços funcionais e cognitivos, como a saída do "isolamento", diminuição das estereotipias, integração entre as crianças (com e sem deficiência) e inclusão escolar na rede regular de ensino.

Após sua formação, o grupo se envolveu com audiências públicas, na cidade do Rio de Janeiro e em Brasília, promovidas por pais que já estavam na "luta" havia mais tempo. Visando "somar forças", lograram a parceria de deputados estaduais e vereadores, assim como o apoio de membros do grupo Azul Claro.

Em 2013, o grupo Azul Celeste obteve reconhecimento na esfera política municipal ao receber duas comendas legislativas "pela luta de informar e conscientizar a sociedade [sobre] o que é o autismo": 8 as medalhas Tiradentes, entregue na Assembleia Estadual do Rio de Janeiro, e Pedro Ernesto, concedida pela Câmara Municipal do Rio de Janeiro. Em um dos eventos, Paulo, membro-fundador do grupo, anunciou publicamente a admiração pelo trabalho da associação de Volta Redonda, ao afirmar que o "sonho do grupo Azul Celeste é ser o Azul Claro". Esse "sonho" representa uma projeção de desempenho positivo, vistos os projetos que associam a conscientização da população à reivindicação de ações direcionadas ao poder público, desde 2011. O que os diferencia, contudo, é o foco almejado: enquanto o Azul Celeste trabalha, particularmente, com as questões associadas à infância e adolescência, como inclusão escolar, diagnóstico e intervenção precoces, o Azul Claro prima pela necessidade de projetos relacionados aos autistas adultos.

A história do grupo Azul Marinho é mais recente. Teve início em 2010, quando, por meio de uma médica em comum, Rita e Roberto - mãe e pai de crianças autistas, respectivamente - foram virtualmente apresentados, embora ambos morassem no Rio de Janeiro. A interação se deu via rede social, até que se encontrassem, meses mais tarde, durante a organização da mobilização que pedia a aprovação do projeto de lei 1698/2011, no Senado, conforme será descrito no primeiro "ato", na seção seguinte. Cerca de sete meses antes da mobilização, vinte pessoas se encontraram no pátio do condomínio de Rita, a fim de discutir e planejar a manifestação "em prol dos direitos dos autistas", a primeira organizada pelo grupo, que, à época, ainda não tinha nome.

Consolidado após a manifestação, o grupo Azul Marinho, ao contrário de instituições como o Azul Claro e o Azul Celeste, concentra suas atividades na

${ }^{8}$ Trecho de frase proferida ao microfone por um deputado estadual que conduzia a solenidade. 
internet $^{9}$ e reúne, atualmente, mais de 30 mil participantes em uma comunidade virtual. Entre os membros-fundadores, cada um desenvolve projetos particulares de alcance coletivo. Hoje, seus objetivos de "luta" estão relacionados, principalmente, às questões da educação e da inclusão no espaço escolar.

Em uma via de mão-dupla, por um lado, o grupo Azul Marinho levanta discussões políticas quando se refere à implementação da lei ํㅡㄴ 12.764/2012, participa de debates acerca do decreto de regulamentação da legislação e compartilha abaixo-assinados com a intenção de pressionar políticos de diversas regiões do país. Por outro lado, marcadamente, aparece menos militante, no sentido das reivindicações públicas, quando os membros dividem suas histórias pessoais, caracterizadas por relatos de dor e de conquistas; pedem ajuda e conselhos e compartilham frases e imagens de incentivo e autoajuda no âmbito virtual.

Para uma participante do Azul Marinho, entrevistada por mim, não é necessário fazer parte de um grupo grande e reconhecido nacionalmente para que se atue politicamente em defesa dos direitos das pessoas com autismo. Quando questionada se mantém contato com outros grupos do país, a informante fez uma leitura particular sobre o Azul Celeste, provocando-nos a pensar que estruturas - familiares, financeiras e emocionais - possibilitam a adesão à militância:

O Azul Celeste é um grupo mais fechado. [...] Eles não deixam você penetrar muito no grupo. [...] Eu observei que cada um dentro da sua área consegue as ajudas, os apoios, os patrocínios. Eles conseguem as coisas, então, é claro que eles não vão deixar qualquer um entrar no grupo. Eles se comprometeram a se doar mais e isso requer uma estrutura que nem todo mundo tem. Por exemplo, a [nome de uma ativista reconhecida no meio] tem uma estrutura na casa dela, então, ela viaja o Brasil todo, ela dá palestra, ela está sempre em Brasília, está sempre visitando os lugares. É ótimo! Mas, ela tem uma estrutura financeira e uma estrutura familiar que permitem isso. Eu participei de várias coisas [eventos] deles e continuo participando. [...] Eles lutam pela lei [12.764/2012], [...] mas o grupo deles é mais para divulgar [o autismo]. [...] Eles abrem para você conseguir um apoio de massa, mas o

\footnotetext{
${ }^{9}$ A internet como instrumento de conhecimento, troca de experiências e campus de pressão política em torno de doenças ou deficiências já foi examinada em trabalhos vinculados à sociologia da saúde, como os de Conrad e Stults (2010), Collins e Evans (2002), Fox, Ward, o'Rouke (2005a; 2005b), entre outros. Sabe-se que a popularização da internet, em meados da década de 1990, trouxe consigo outras formas de os indivíduos se relacionarem e experimentarem a própria condição.
} 
núcleo deles é fechado. Eu não sou contra isso, não. É uma estrutura que eles montaram e está dando certo para eles. [...] É uma atitude que algumas pessoas se magoam e se afastam. Eu compreendo, mas ainda não chegou o meu momento de me doar desse jeito, não tenho estrutura financeira.

Nesta pesquisa, uma parte dos meus informantes é formada por pais de autistas ainda crianças, ou seja, pessoas legalmente sob jurisdição dos pais. A outra é constituída por pais e familiares de adultos considerados "severos", "clássicos" e "moderados", que não tiveram acesso à informação e a serviços adequados, sobretudo porque o autismo era pouco conhecido e divulgado, mesmo entre a classe médica.

Esta seção procurou focalizar as dinâmicas de atuação privilegiadas pelos três grupos. Em comum, os grupos Azul Claro, Azul Celeste e Azul Marinho são constituídos, exclusivamente, por pais e familiares de autistas. Compartilham discursos pautados na "luta por direitos", a partir do reconhecimento da categoria "deficiência" como instrumento político-identitário (DINIZ, 2007; SASSAKI, 2005, 2012). Os grupos Azul Claro e Azul Celeste, em especial, constituem duas das associações de pais de autistas de maior representatividade política junto ao poder público, no estado do Rio de Janeiro. A análise de ambas revelou a imprescindibilidade da construção de "parcerias" entre sociedade civil, políticos e empresários, para que se formulem legislações e se assegurem direitos específicos. Somente no estado do Rio de Janeiro, estes grupos foram responsáveis pela pressão que resultou na sanção de leis referentes ao diagnóstico precoce e à construção de centros de atendimento especializados em autismo. ${ }^{10}$

Conforme será descrito a seguir, por um lado, os três grupos visam atingir o poder público e a sociedade, valendo-se de artifícios de visibilidade e das gramáticas dos direitos humanos. Por outro lado, no nível local, detêm configurações estruturais peculiares que ora os afastam, ora os aproximam. Na seção seguinte, interessam-me as manifestações de caráter público que focalizam as autoridades parlamentares e a sociedade, de modo a apreender as incorporações de performances que mobilizam, a um só tempo, afetos, emoções, política e direitos.

\section{Desenhando o campo}

${ }^{10}$ Até o momento, não houve, de fato, a implantação de nenhum dos centros previstos. 
Nesta seção, a ideia é desenhar as principais atividades formuladas por sujeitos coletivos, realizadas, durante o período que se deu a pesquisa, em conjunto ou autonomamente, pelos grupos Azul Claro, Azul Celeste e Azul Marinho. Estes eventos indicam tanto a minha entrada no campo quanto os processos de construção da visibilidade de demandas e vocalizações em nome dos "autistas brasileiros". Portanto, detalharei, em três atos, parte do trabalho etnográfico desenvolvido para pesquisa mais ampla, que deu origem à dissertação de mestrado (NUNES, 2014). A noção de "ato" nos subtítulos da seção se refere não apenas à minha atuação como pesquisadora e à de pais de autistas como informantes qualificados. Trata-se também de pensar os cenários do trabalho de campo como regiões de significação, com regras definidas que circunscrevem as interações entre os atores (GOFFMAN, 2005).

Embora tenha tido a oportunidade de acompanhar uma diversidade de "atos", como estratégia metodológica focalizarei aqueles que tiveram projeção nacional, sendo realizados, simultaneamente, por outras organizações, em demais cidades e estados do país. A descrição dos atos será realizada de acordo com a ordem cronológica em que ocorreram.

Primeiro ato: Cidade Nova, prefeitura do Rio de Janeiro, 19 de setembro de 2012

O momento elucidava expectativas. Àquela altura, o projeto de lei $\mathrm{n}^{\mathrm{o}}$ 1698/2011 já havia sido aprovado na Câmara dos Deputados e aguardava apreciação no Senado Federal. Tratava-se do primeiro projeto formulado por pais e familiares de autistas a ser aplicado em âmbito nacional. Intituladas "pró-direitos dos autistas", manifestações surgiram em diversas cidades brasileiras para dar visibilidade à "luta" e pedir urgência na aprovação do projeto, que reconhecia o autista como pessoa com deficiência. Na cidade do Rio de Janeiro, o local escolhido foi a sede da prefeitura, no Centro da cidade.

Eu soube da manifestação poucos dias antes e decidi acompanhá-la como estratégia de aproximação dos militantes do autismo no Rio de Janeiro. Ao sair do metrô, avistei quatro pessoas conversando e segurando dois banners ainda fechados. Imaginei que estivessem ali para o protesto e, ao mesmo tempo, notei a quantidade ínfima de participantes. Antes de me aproximar, era minha intenção observar a interação entre aquele pequeno grupo, formado, ao todo, por seis mães, um pai e uma tia de autistas. Não havia autistas presentes.

No entanto, a cor azul da minha blusa chamou a atenção daquele pequeno público, que me identificou como uma manifestante em potencial. Uma das mães caminhou em minha direção e indagou: "você está aqui para a manifestação? Fique com a gente!”. De observadora passei a observada e, em seguida, à participante do evento: carreguei faixas, segurei balões azuis e distribuí folhetos explicativos para os transeuntes. Apresentei-me, desde o início, como pesquisa- 
dora e, resumidamente, falei sobre meu projeto de pesquisa.

Foi por meio da internet, em redes sociais, que os participantes da mobilização se conheceram e programaram o evento. Após questioná-los se mantinham vínculo formal com algum grupo ou instituição, os pais presentes negaram, embora Renata e sua irmã estivessem usando uma camisa do grupo Azul Celeste. ${ }^{11}$

Para a manifestação do dia 19 de setembro, foram impressos folhetos intitulados "Você conhece o autismo?", nos quais se encontravam descritas as principais características da deficiência, além de duas cartas, redigidas por participantes do grupo, acerca da importância da aprovação da legislação sobre a qual tratava a mobilização. Com balões azuis em mãos, o grupo atraiu a atenção das pessoas que passavam pelo local. Um senhor, de aproximadamente 70 anos, parou-me para perguntar o que era autismo. Dei uma explicação bastante superficial, tal como "é uma dificuldade na interação, na comunicação e socialização". Ainda sem compreender, indagou-me: "autismo é um problema de visão?". Interessada em saber qual seria a resposta de um dos familiares, pedi à Rita que falasse com o homem. Rita gaguejou inicialmente e também resumiu o autismo a uma condição particular de comunicação e de comportamento. Sem dar maiores detalhes, disse-lhe que estavam ali para pedir a aprovação da "Lei dos autistas". O senhor saiu satisfeito com a resposta, pediu um folheto e voltou ao seu posto de trabalho, uma carrocinha de pipoca.

Após duas horas e meia em frente à Prefeitura, os balões de gás foram soltos pelos pais, formando nuvens azuis. Tive permissão para fotografar o momento e, para as mães que portavam suas próprias câmeras, também atuei como fotógrafa. Dias após a manifestação em frente à prefeitura, os familiares criaram a página virtual do grupo Azul Marinho, no Facebook. A organização do ato foi totalmente autônoma, contando com a contribuição financeira de pais que "têm condições" de ajudar, segundo uma das mães presentes.

\footnotetext{
${ }^{11}$ Alguns participantes confirmaram a participação em encontros e eventos promovidos pelo Azul Celeste, o que tornou claro, pela primeira vez, para mim, a troca de informação e o diálogo entre os grupos.
} 


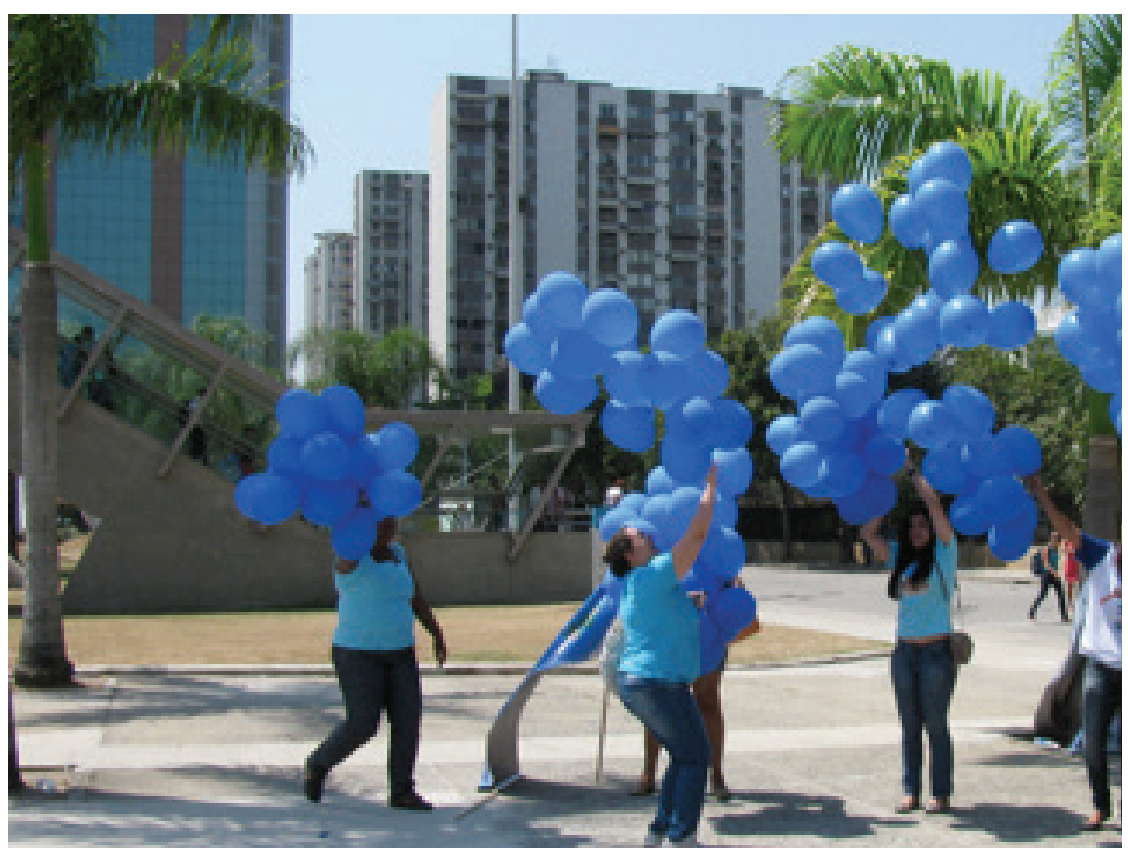

Figura 1 Manifestantes soltam os balões azuis, em frente à Prefeitura do Rio de Janeiro. Fonte: Nunes, 2012.

Durante a conversa com um dos pais que organizou o movimento, percebi que o argumento central referente ao projeto de lei girava em torno do ineditismo de uma legislação federal específica para autistas. Segundo Roberto, pai de uma menina autista "não verbal", sem o respaldo da legislação os acessos a diagnósticos precoces, tratamentos e educação ficariam prejudicados.

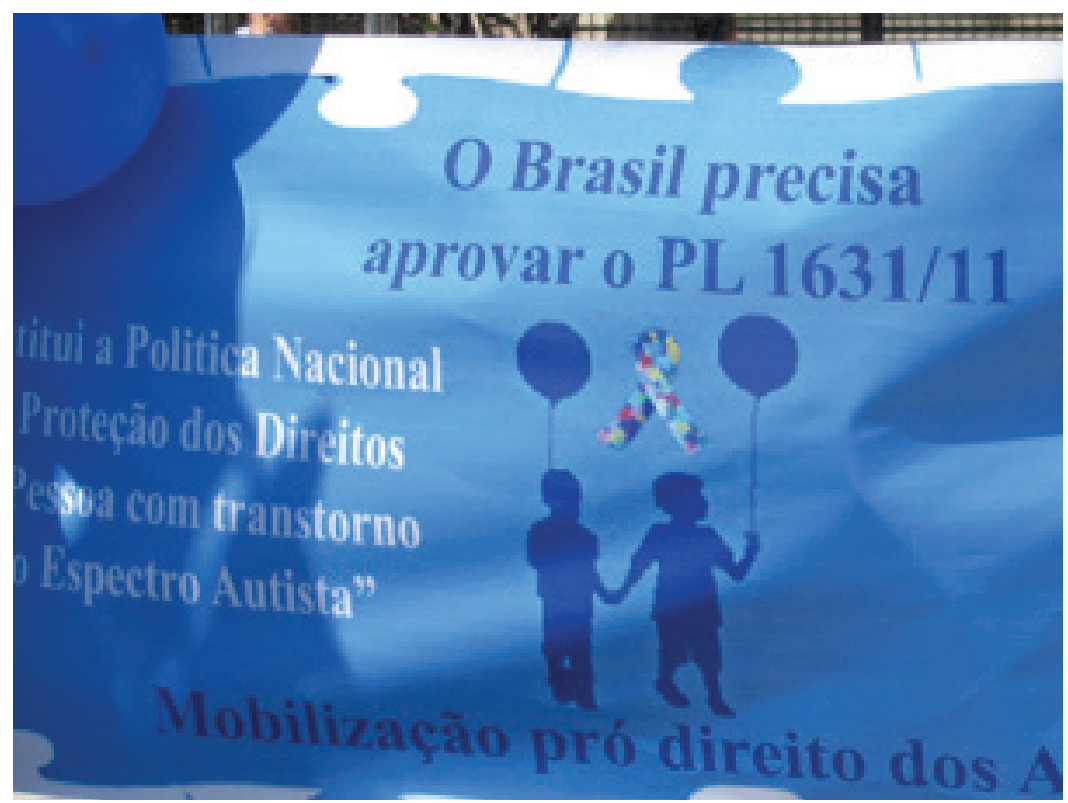

Figura 2 Detalhe da faixa azul carregada por pais de autistas, pedindo a aprovação da "Política Nacional de Proteção dos Direitos da Pessoa com Transtorno do Espectro Autista". A imagem mostra a bandeira do Brasil junto ao símbolo universal do autismo, além da silhueta de duas crianças de mãos dadas. Fonte: Nunes, 2012. 
Segundo ato: Cristo Redentor, 2 de abril de 2013

Desde 2011, ocorre a cerimônia de iluminação do Cristo Redentor com a cor azul, no Dia Mundial de Conscientização do Autismo, decretado pela Organização das Nações Unidas (ONU), em 2008. A data foi criada com a finalidade de conscientizar a sociedade civil e os Estados-membros de que o autismo, segundo a ONU (2007)

é uma deficiência que se manifesta durante os três primeiros anos de vida e resulta de uma desordem neurológica que afeta o funcionamento do cérebro, em crianças de vários países independente do gênero, raça ou condição socioeconômica, e caracteriza-se pelo dano na interação social, problemas nas comunicações verbal e não verbal, bem como comportamentos e interesses restritos e repetitivos.

Como ações principais, diante do alto índice de diagnóstico de autismo, o documento oficial propõe que os Estados-membros invistam em diagnóstico precoce, pesquisas e intervenções "vitais para o crescimento e desenvolvimento do indivíduo".

No Brasil, além do Cristo Redentor, receberam a iluminação azul monumentos como a Ponte Estaiada, em São Paulo, e os prédios do Senado Federal e do Ministério da Saúde, em Brasília. Outros eventos, como palestras sobre o tema, caminhadas e distribuição de material informativo, foram promovidos por diversas associações brasileiras. Na cidade do Rio de Janeiro, o grupo Azul Celeste também realizou a III Caminhada pela Conscientização do Autismo, na praia do Leblon, contando com a presença da apresentadora Xuxa Meneghel como forma de alcançar maior visibilidade para a causa. ${ }^{12}$

Celso, pai de Lucas, foi responsável por conseguir autorização para a iluminação do Cristo Redentor, que recebeu, em julho de 2007, o título de Sétima Maravilha do Mundo Moderno. Inspirado pelo movimento americano Autism Speaks, ${ }^{13}$ Celso justificou a escolha do Cristo como monumento a ser iluminado de azul:

\footnotetext{
${ }^{12}$ Gohn (1997, p. 238) considera que "os Novos Movimentos Sociais (...) usam a mídia e as atividades de protesto para mobilizar a opinião pública a seu favor. (...) Criar fatos novos que gerem impactos e virem notícias na mídia é uma preocupação permanente da maioria dos movimentos sociais".

${ }^{13}$ A Autism Speaks foi fundada em 2005 e investe recursos próprios em apoio a pesquisas que focalizem a causa, prevenção, tratamento e cura para o autismo. Em 2007, outra grande organização formada por pais de autistas, médicos e pesquisadores, chamada Cure Autism Now, se fundiu à Autism Speaks, a fim de fortalecer o financiamento e a produção de pesquisas biomédicas.
} 
Eu tinha conseguido iluminar o Cristo de azul a partir do movimento americano Autism Speaks, porque eles viviam iluminando o Empire State [Building] e vários monumentos de azul. Então, uma mãe [de autista] me sugeriu: "Vamos iluminar alguma coisa de azul, alguma coisa grande, que chame atenção”. Aí, eu pensei: “Uma coisa grande que chame atenção' só pode ser o Cristo Redentor!”. Aí, eu fui tentar o caminho [com a administração do Cristo] e consegui manter um processo. Falei que o objetivo era ajudar pessoas que não tinham tratamento. Eles entenderam, não me cobraram nada e iluminamos o Cristo Redentor de azul. (Entrevista concedida em agosto de 2013)

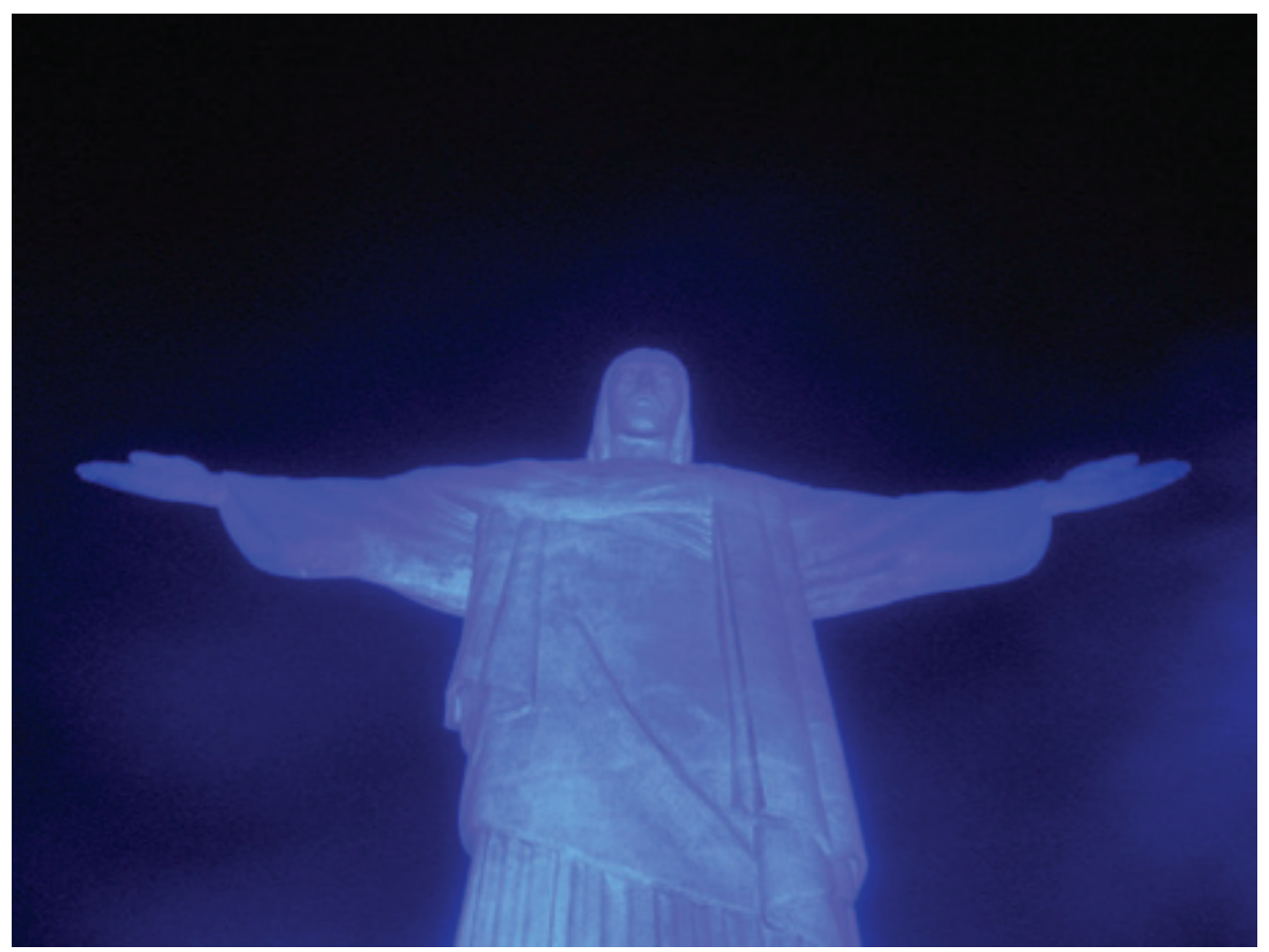

Figura 3 Cristo Redentor iluminado na cor azul. Fonte: Nunes, 2013.

No dia 2 de abril de 2013, cerca de quinhentas pessoas se encontraram sob os braços do Cristo Redentor, entre autistas, representantes de associações, pais, familiares, profissionais da saúde e da educação, além de figuras políticas. A imprensa também esteve presente para cobrir o evento.

Ao chegar, identifiquei a presença de figuras conhecidas no campo dos movimentos sociais do autismo no Rio de Janeiro. No local, havia cadeiras dispostas em fileiras, mas a maioria das pessoas estava em pé. Marcado para começar às dezoito horas, o evento promovido pelo grupo Azul Celeste teve apoio de empresas e de um banco privado. Com duração de cerca de duas horas, constituiu um dos primeiros locais de discurso público sobre a conquista da recém-aprovada lei no 12.764/2012, a chamada "Lei do Autista".

Durante a cerimônia, foram entregues "medalhas do mérito autista", criadas 
para homenagear, segundo um dos fundadores do grupo, "homens e mulheres que se destacaram na luta incansável em favor da causa do autista". Essa "luta" se refere, principalmente, ao processo de construção de uma identidade coletiva e à aprendizagem política (SANTOS, 2005; GOLDMAN, 2007), pelos quais passaram grande parte dos participantes do evento, culminando na sanção da legislação que ganhou status de "troféu" dos movimentos de pais de autistas no Brasil.

O êxito da legislação específica para o espectro do autismo, afirmaram os fundadores do grupo Azul Celeste, foi alcançado por meio da consolidação de "parcerias". Assim, como forma de agradecimento aos "parceiros" que estiveram presentes no percurso até a sanção da lei no $12.764 / 2012$, a entrega das medalhas foi dirigida a empresários, políticos, pessoas da mídia, presidentes de outros grupos de pais de autistas, profissionais da saúde, além do padre Omar Raposo, reitor do santuário do Cristo Redentor. Na ocasião, também foram nomeadas "madrinhas azuis", entre as quais figurava a presidente da República Dilma Rousseff, ${ }^{14}$ e "padrinhos azuis". Essas homenagens e nomeações simbólicas deixam claro que as "parcerias" - principalmente por meio do apoio de figuras políticas - são indispensáveis na trajetória de "luta" por direitos e por reconhecimento.

$\mathrm{Na}$ via da emoção, um telão disposto próximo ao monumento exibiu o trailer do filme ficcional Arthur e o infinito - um olhar sobre o autismo, que retrata a relação e os dilemas cotidianos de uma mãe de criança autista. Encerrando a cerimônia, houve a apresentação da música "Con te partiro" por Saulo Laucas, tenor que é autista e cego.

Terceiro ato: Leblon (RJ) e Bairro Santa Cecília (VR), 1ำ de setembro de 2013

A partir de junho de 2013, observaram-se pleitos e críticas direcionados "ao governador" e "ao prefeito" do Rio de Janeiro, marcando um período específico da história política do país. ${ }^{15}$ Como parte dessa conjuntura nacional, manifestações com faixas, camisetas e balões ganharam contornos de protesto e não apenas de mobilização por reivindicações.

Mais uma vez, a internet agiu como ferramenta privilegiada na circulação de ideias e como arena de ressignificação de ações. Nas redes sociais e listas de e-mails, organizadores do evento convocaram "profissionais, familiares e ami-

\footnotetext{
${ }^{14}$ A homenagem se deu em forma de agradecimento pela sanção da "Lei do Autista", em 2012 (lei no 12.764/2012).

${ }^{15}$ Desde de junho de 2013, pouco antes da Copa das Confederações, manifestações Brasil afora surgiram contra o aumento das tarifas do transporte público, sob o argumento de que "não é pelo valor das passagens. É por direitos”. Marcadas por violentos confrontos entre policiais e manifestantes e pela prisão contestável de participantes, as manifestações seguintes tiveram diversas reivindicações em pauta, marcando a configuração heterogênea do público e das demandas: "contra a corrupção", "contra o valor das passagens", contra a "falta de investimento em saúde e educação", contra o superfaturamento das obras realizadas para a Copa do Mundo, contra a "violência policial", em especial o caso "Cadê o Amarildo?” e contra a aprovação da PEC 37.
} 
gos" de autistas a participarem da "Mobilização Nacional em favor do cumprimento da lei no 12.764 ", realizada no dia $1^{\circ}$ de setembro de 2013, domingo, às nove horas. Toda a mobilização foi dirigida ao poder público, tendo como viés a pressão para implantação de "Centros de Tratamento Integral para Deficientes Mentais e Autistas no Rio de Janeiro", sob as diretrizes da lei estadual $\mathrm{n}^{\mathrm{o}}$ 6.169/2012, de autoria do deputado estadual Xandrinho (PV/RJ), em conjunto com o grupo Azul Celeste.

O ato ocorreu na Avenida Vieira Souto, Leblon, bairro com um dos IPTUs mais elevados do Rio de Janeiro, onde vivia o então governador do estado, Sérgio Cabral. Embora parte da rua estivesse fechada e cerceada por policiais militares, como "medida de segurança", 2 mil pessoas, em média, estiveram presentes portando faixas que denunciavam a situação de exclusão em que vivem "os autistas", assim como cartazes irônicos onde se lia "Desculpe o transtorno, nossos filhos não têm tratamento", além de blusas azuis com a frase que remetia ao momento de saída da suposta letargia política dos cidadãos brasileiros: "O gigante acordou. Cumpra-se a Lei do Autista”.

Obtive essas informações por meio de vídeos, fotos e textos largamente compartilhados por familiares de autistas na internet. Nessa ocasião, contudo, optei por acompanhar de perto a mobilização organizada pelo grupo Azul Claro, no município de Volta Redonda, devido à sua menor proporção quando comparado ao município do Rio de Janeiro. Ademais, vista minha maior proximidade com este grupo, fui convidada a participar do processo de confecção de faixas e cartazes utilizados para o evento. A mobilização ocorreu na praça Brasil, onde, segundo os organizadores do evento, seria dada maior visibilidade à causa, por ser uma área de grande movimento, mesmo nos fins de semana. Anteriormente à escolha do local, houve votação, via rede social, para saber se os moradores de Volta Redonda estavam dispostos a participar da manifestação mais ampla (em geral, o prefeito disponibiliza vans ou ônibus para o traslado dos moradores), na cidade do Rio de Janeiro, ou se preferiam realizar um evento independente em Volta Redonda. A segunda opção foi a mais votada.

No dia do evento, porém, apenas cerca de cem pessoas, entre autistas, familiares e profissionais, se reuniram em torno da praça. Vestidos de azul e munidos de balões, faixas e cartazes, gritaram palavras que evidenciavam a importância da sanção da lei no 12.764/2012, como “Com a lei, Volta Redonda vai além!”, e clamaram a atenção do poder público às particularidades dos autistas adultos, da implantação dos centros de atendimento específicos para autistas e das residências assistidas.

Ao contrário do evento maior, que se posicionou contra o descaso do governador e do prefeito com relação à "causa autista", os membros do Azul Claro optaram por realizar uma manifestação que contava com a participação de figuras políticas, tais como dois vereadores. Os legisladores fizeram novas "promessas" de atendimento à urgência na implantação de serviços especializados em autismo, 
como os "Centros de Atendimento Integral para Autistas", mediante a legislação já sancionada, e dividiram o microfone disponível com a nova presidente do grupo Azul Claro e com outros pais e familiares. Pessoas com autismo também puderam expor seus pensamentos de forma livre: algumas crianças cantaram e um autista adulto contou ao público sobre seu cotidiano, que envolve a prática de esportes em uma organização não governamental, curso de teatro e trabalho assalariado na prefeitura de um município vizinho. A mobilização durou no máximo duas horas e contou com a participação de pessoas e instituições de cidades próximas.

A ideia inicial era que o prefeito da cidade comparecesse ao evento. Entretanto, naquele momento, o alcaide havia sido afastado por motivo de "crime eleitoral", tendo retornado ao cargo dois dias depois. A sanção de três legislações municipais referentes ao autismo na região, não raro, é atribuída à relação de "parceria" com o prefeito, que está em seu quarto mandato. Em 2012, inclusive, ele recebeu a placa de "amigo dos autistas" das mãos de familiares do grupo Azul Claro.

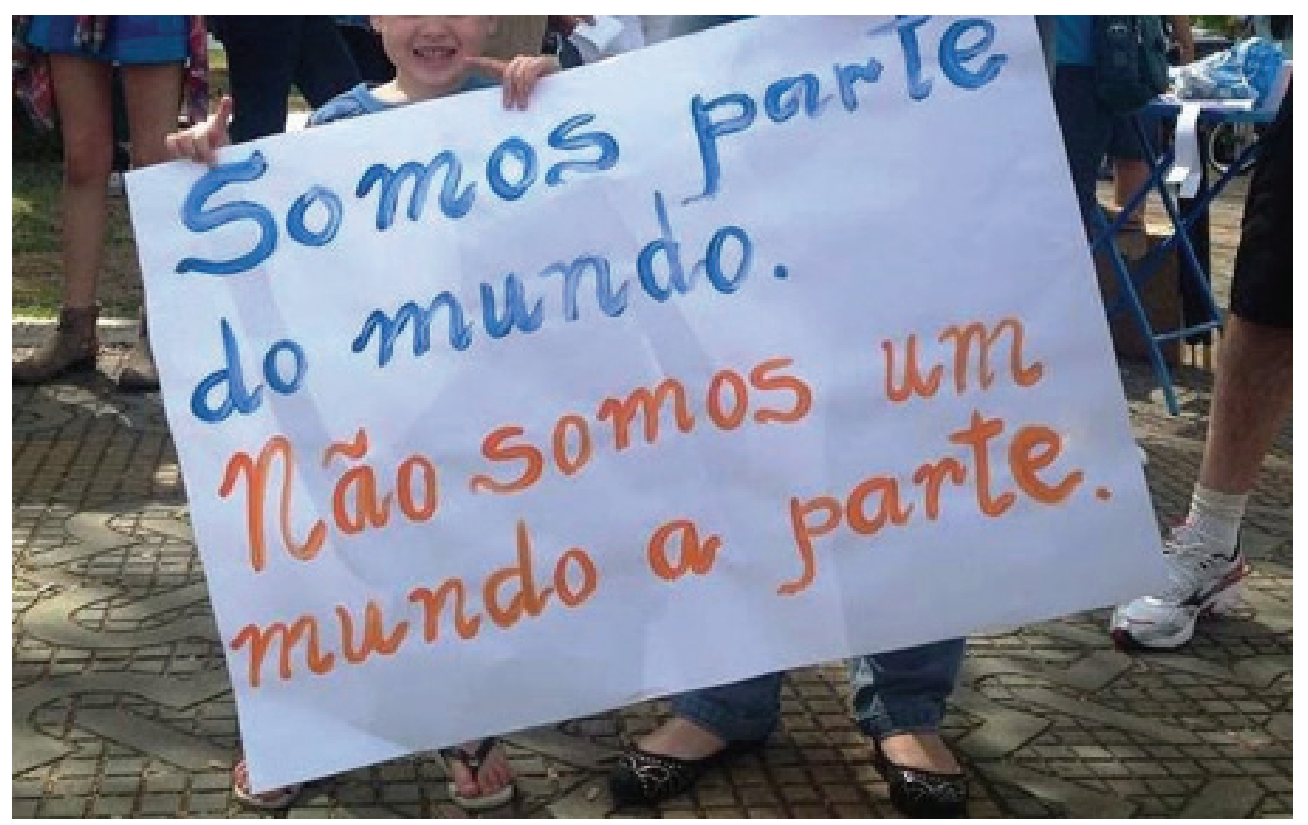

Figura 4 Detalhe de um cartaz, na mobilização de 1ํ de setembro, em Volta Redonda, em que se lê "Somos parte do mundo. Não somos um mundo à parte". Fonte: Grupo Azul Claro, 2013.

\section{Do híbrido: sobre pais, mães e ativistas}

O surgimento de novos agentes de pressão social e de outros tipos de reivindicações possíveis, dirigidos ao Estado mas também à sociedade em geral, trouxe à luz pleitos por direitos humanos, reconhecimento de identidades, participação social e equidade (ALONSO, 2009). À frente, estão atores que fazem de seus respectivos corpos, práticas e saberes o próprio campo de ação política. Quando levam às ruas e ao parlamento situações particulares que expõem a invisibilida- 
de e as ausências sofridas pelos "autistas brasileiros" e suas famílias, esses atores passam a encarnar a diversidade de papéis sociais envolvida na separação entre os espaços da casa e da rua (DAMATTA, 1985).

Ser pai ou mãe de autista, nos termos dos meus informantes, é enfrentar situações de preconceito, isolamento social e dificuldades relacionados ao próprio cuidado do filho. No entanto, ser pai ou mãe ativista implica prestígio e reconhecimento público por parte de outros pais, grupos e políticos. Ao apontar para a necessidade de uma agenda de pesquisa que contemple questões da vida privada dos familiares de autistas, Celso, participante do grupo Azul Celeste, criou a categoria "pais-problema", em referência à disrupção dos laços afetivos e sociais vivenciada por essa parcela da população:

Quando um pai e uma mãe recebem um filho com autismo, tem aquela vertente que reage, vai para as terapias e tratamentos; e tem aquela outra vertente dos pais que quer recusar e diminuir o problema. Mas, dentro desse universo, os pais se sentem, de certa forma, tachados como "pais-problema". Isso seria objeto de uma pesquisa muito grande, porque os pais se sentem excluídos do próprio convívio familiar, no sentido de que quando aquele pai chega [nos lugares], [também] chega aquela criança que derruba tudo, que fala alto e que não fica quieta. Então, para festas de criança nós não somos mais chamados. Isso é notório. Se você perguntar aos outros pais: "Como é a vida social de vocês? Mudou alguma coisa? Os amigos que vocês tinham antes... Como é o depois? Vocês continuam saindo, indo ao teatro? [...]”. Então, isso é um verdadeiro impacto. É como se uma bomba de nêutrons - aquela que mata tudo em volta, mas não destrói nada tivesse explodido nos nossos relacionamentos.

Segundo meu informante, não são apenas o preconceito ou a falta de informação acerca do comportamento diferenciado do filho autista que os tornam rotulados como "pais-problema", mas também a adesão desses sujeitos ao movimento social, tomada como um propósito de vida. Assim, o seguinte trecho da entrevista reflete parte de sua dupla experiência com o autismo, enquanto "pai do Lucas" e "militante":

Com quinze anos [de experiência] ouvindo pais, eu arrisco dizer, com quase certeza, que setenta, oitenta por cento dos pais têm uma perda de vida social tremenda. A vida social vai embora. A vida conjugal sofre um impacto também, tremendo. [...] Na sociedade familiar, avós, tios, são raros aqueles que se organizam para nos ajudar, que seja, não só financeiramente, 
mas se revezando para levar [o autista] para tratamento. [...] Nós acabamos criando um grupo seleto de pessoas que falam só sobre os mesmos problemas. Isso é bom e é ruim. É bom porque potencializa o nosso campo de atuação, mas é ruim porque nós começamos a nos fechar também. [...] E eu acabo falando só sobre isso, no trabalho, no ponto de ônibus. Virou meu tema. Infelizmente, entre aspas, eu respiro isso. [...] E, se nós tivéssemos uma sociedade mais apta para os autistas, talvez eu não fosse viver isso, mas eu precisei viver isso, o que, para mim, se tornou um estigma: eu sou conhecido como o cara que fala de autismo. Mas ao mesmo tempo, quando alguém tem um problema, sabe a quem recorrer.

É com a entrada no ativismo que familiares de autistas diferem dos demais, tornam-se referências às quais se pode "recorrer". Por outro lado, é na militância que constroem seu círculo de amizades, embora "fechado". Como previu Celso, percepções semelhantes às dele apareceram em outras entrevistas concedidas a mim.

Ao ressignificar o conceito de autismo, Suzana, do grupo Azul Claro, classificou sua atuação como "tomada de posição dentro da sociedade". Suas palavras corroboram as de Celso:

$\mathrm{Na}$ minha concepção, o autismo é aquilo que mudou a minha vida. [...] O autismo mudou a minha vida radicalmente. Eu acho que hoje eu sou uma pessoa completamente diferente. Os amigos que eu tenho estão nesse meio. Eu me descobri como uma pessoa dinâmica nesse meio, uma pessoa criativa [...]. O meu filho mesmo é uma pessoa que determinou uma mudança geral em tudo. $\mathrm{O}$ autismo para mim é isso: é essa tomada de posição dentro da sociedade. Hoje, eu sou uma pessoa atuante dentro dessa sociedade. As pessoas, às vezes, falam assim para mim: "Ah, eu tenho uma pena de você. É uma cruz [ter um filho autista], não é?”. Gente, é completamente diferente! Hoje em dia, é a minha vida, é o que eu faço. Se não tivesse o autismo na minha vida, eu não seria eu. E eu sinto, assim, que eu consigo ajudar outras pessoas com uma palavra, com um gesto.

Do momento em que se é identificado/rotulado negativamente ("pessoa chata que só fala de um assunto", por exemplo) à construção da carreira de desviante, que se dá pela politização e coletivização de uma experiência subjetiva, há uma mudança drástica na identidade pública do indivíduo. A construção da carreira desviante é aqui entendida como a passagem do "pai”/“mãe”, cujo saber 
é leigo, para o "ativista", que marca efeitos positivos da experiência de transformação do self (BECKER, 1963; GOFFMAN, 1988).

A etnografia dos eventos públicos promovidos por grupos de pais de autistas procurou mostrar que a categoria "pai ativista" não se constrói apenas pela condição de se ter um filho autista. É um trabalho que mobiliza afetos e luta política e exige, assim, a reconfiguração da identidade de "pai" e de "mãe". Falar somente a partir de uma experiência particular de amor incondicional ao filho, por si só, não constitui ação política.

As narrativas dos que chamo de "pais ativistas" mostraram que a incorporação ao movimento social envolve largo processo de expertise política, aprendizagem de termos médicos, técnicos, legislativos e jurídicos, assim como de trâmites burocráticos e negociações junto a vereadores, deputados, senadores e ministros (EPSTEIN, 1995; VIANNA; FARIAS, 2011; LACERDA, 2012).

De acordo com a socióloga e pesquisadora dos estudos feministas Patricia Clough (2007; 2010), a "virada afetiva" trouxe como novidade a incorporação do "trabalho afetivo", à luz da produção feminista norte-americana da década de 1990. Nesse período, destacou-se o trabalho emocional de cuidadores, sob o viés das relações de gênero, cuidado e dependência, tanto em contextos remunerados quanto não remunerados. Para Clough, o trabalho afetivo mobiliza atividades em que corpo e mente, razão e emoção, estão simultaneamente engajados e têm implicações diretas no campo da política. Superando as dicotomias entre cuidador/pessoa dependente; homem/mulher; público/privado; cultura/natureza, esses estudos mostram como a deficiência se tornou um marcador de interseccionalidade importante, junto com raça, classe, etnia, entre outros (CROW, 1996; KITTAY, 1998; 2001).

Segundo Diniz (2007, p. 5), a aproximação entre os estudos da deficiência e outros saberes, ao desafiar a autoridade biomédica, resultou na descrição da deficiência "em termos políticos e não mais estritamente diagnósticos". Nesse sentido, o reconhecimento da deficiência e a adesão ao movimento social constituem partes do processo de subjetivação da experiência que permite a transformação dos sujeitos, "contrapondo-se às ideias hegemônicas de tratá-la [a deficiência] tão somente como um fardo, desvio, aberração, perturbação ou anormalidade" (MELLO, 2009, p. 40).

No "ato" organizado pelo grupo Azul Celeste, a fundadora Marta pediu para que pais e familiares de autistas vocalizassem, em uma só palavra, o que o termo "autismo" representa. Não houve nenhuma descrição como categoria médica, mas sim a partir do emprego de palavras-símbolo daquilo que "vivenciam na pele". Os substantivos e adjetivos citados foram divididos como "positivos" (17) e "negativos" (6), a fim de mostrar ao público que "ter um autista em casa” significa a compatibilização de experiências híbridas e sentimentos nuançados. Algumas delas, como "amor", "desafio", "estímulo”, "persistência”, "união”, "desinformação", 
"isolamento" e "preconceito", apareceram com frequência nas narrativas ouvidas por mim ao longo do trabalho de campo, independente do grupo analisado.

Cabe ressaltar que a construção de uma identidade coletiva positiva é também comumente evidenciada por meio da autoclassificação de familiares como "pais de anjos azuis", "pais especiais", "mães azuis" e "família azul”. Embora entenda que o uso desses termos implica parte da construção de uma identidade, é importante salientar que palavras como "especial" e "anjos" são consideradas eufemismos que minimizam o estatuto de sujeito de direitos da pessoa com deficiência, além de denotar capacitismo. ${ }^{16}$

De acordo com Silverman (2012), o "amor" dá sentido a escolhas práticas e terapêuticas e é uma forma de expertise que transforma pais e mães de autistas em "especialistas-amadores", ou "especialistas de seu próprio filhos", para usar os termos de Schopler e Reichler (1971). É este tipo de expertise que legitimará decisões individuais, mesmo as mais controversas, e permitirá o diálogo com especialistas "formais" do tema. Silverman observou, porém, que a função de "pai" ou "mãe" não assegura que as melhores opções serão selecionadas, nem que eles detêm mais autoridade que a própria criança acerca de sua condição. $\mathrm{O}$ que essa identificação envolve é, na verdade, "um entendimento muito íntimo e específico dos caráteres físico e emocional da criança, após anos de observação e experiência" (2012, p. 134).

Neste artigo, vimos que a gramática dos afetos, apreendida no uso de termos como "amor", "união", "esperança" e "família", presente em falas e cartazes, coaduna necessariamente com a gramática dos direitos humanos, quando se evidenciam, sobretudo, as situações de exclusão e preconceito, as ausências de diagnóstico precoce e os descasos enfrentados nos serviços de saúde e de educação. Portanto, a soma desses elementos, como instrumento de performance dos grupos, aciona tanto a atenção da sociedade quanto convence figuras políticas da urgência de ações voltadas ao autismo. Em suma, criam-se "parcerias", "informação" e "conscientização".

\section{Considerações finais}

Segundo Velho (1989), a relevância das pesquisas de caráter etnográfico reside justamente na observação da multiplicidade de experiências vividas, fluidas e maleáveis, que exclui a possibilidade de fixidez. Este trabalho, ao tratar do par autismo/política, concebe o ativismo em torno das demandas realizadas por movimentos de pais de autistas do Rio de Janeiro como algo irredutível ao sistema biomédico. A politica das diferenças é, por conseguinte, construída na ressignificação da experiência subjetiva do autismo (ou de se ter um filho autista), que

${ }^{16}$ Capacitismo é a tradução brasileira feita para o neologismo "ableism". O termo aborda a concepção de que pessoas com deficiência não são iguais, são incapazes, menos aptas que as outras. 
"contamina" e "é contaminada" pela esfera pública de atuação, na tensão entre trajetórias biográficas e participação política.

Como visto, a deficiência como categoria tornou-se premissa importante para o reconhecimento de direitos. A politização do autismo é assim compreendida como medida necessária para atender pleitos de diferentes ordens, em nome dos "autistas brasileiros". As atuações dos grupos de autistas variam em suas formas, mas constituem um processo que conjuga elementos e afetos particulares à aprendizagem de termos técnicos, jurídicos, legislativos na esfera das reivindicações coletivas por direitos.

\section{Referências bibliográficas}

ALONSO, Angela. As teorias dos movimentos sociais: um balanço do debate. Lua Nova, v. 76, p. 49-86, 2009.

AMERICAN PSYCHIATRIC ASSOCIATION (APA). Diagnostic and Statistical Manual of Mental Disorder. DSM-5, Arlington, VA: American Psychiatric Association, 2013.

ASSIS SILVA, César Augusto. Cultura surda: agentes religiosos e a construção de uma identidade. São Paulo: Terceiro Nome, 2012.

BECKER, Howard. Outsiders: studies in the sociology of deviance. Nova York: Free Press, 1963.

BRASIL. Lei n 10.216, de 6/4/01. Dispõe sobre a proteção e os direitos das pessoas com transtornos mentais e redireciona o modelo assistencial em saúde mental. Brasília: 2001.

Convenção sobre os Direitos das Pessoas com Deficiência. Protocolo Facultativo à Convenção sobre os Direitos da Pessoas com Deficiência. Tradução Oficial/Brasil. Brasília: Secretaria Especial de Direitos Humanos (SEDH); Coordenadoria Nacional para a Integração da Pessoal Portadora de Deficiência (Corde), 2008.

BROWN, Phil; ZAVESTOSKI, Stephan. Social Movements in Health: an introduction. Sociology of Health and Illness, v. 26, n. 6, p. 679-694, 2004.

CENTERS FOR DISEASE CONTROL AND PREVENTION (CDC). Prevalence of Autism Spectrum Disorders (ASDs) Among Multiple Areas of the United States in 2008. U.S. Department of Health and Human Services, 2012.

CLOUGH, Patricia. Introduction. In: The Affective Turn: theorizing the social. Durham: Duke University Press, 2007.

Afterword. The future of affect studies. Body \& Society, n. 16, 2010.

CROW, Liz. Including All of Our Lives: renewing the social model of disability, in: BARNES, C.; MERCER, G. (Orgs.). Exploring the Divide. Leeds: Disability Press, 1996.

CONRAD, Peter; STULTS, Cheryl. Internet and the Eexperience of Illness. In: BIRD, C. et al. (Orgs.). Handbook of Medical Sociology. Nashville: Vanderbilt 
University Press, 2010.

COLLINS, Harry M.; EVANS, Robert. The Third Wave of Science Studies: studies of expertise and experience. Soc. Stud. Sci., v. 32, n. 2, p. 235-96, 2002. FOX, Nick; WARD, Katie; O’ROURKE, Alan. The "Expert Patient”: empowerment or medical dominance? The case of weight loss, pharmaceutical drugs, and the internet. Soc. Sci. Med., v. 60, n. 6, p. 1299-309, 2005a.

Pro-Anorexia, Weight-Loss Drugs, and the Internet: an "anti-recovery" explanatory model of anorexia. Sociol. Health Illn., v. 27, n. 7, p. 944-71, 2005b.

DAMATTA, Roberto. A casa e a rua. São Paulo: Brasiliense, 1985.

DINIZ, Débora. O que é deficiência. São Paulo, Ed. Brasiliense, 2007.

EPSTEIN, Steven. Impure Science. AIDS, activism, and the politics of knowledge. Berkeley, Los Angeles, Oxford: University of California Press, 1996.

GOFFMAN, Erving. Estigma: notas sobre a manipulação da identidade deteriorada. 4.ed. Rio de Janeiro: Guanabara, 1988.

A representação do eu na vida cotidiana. Petrópolis: Vozes, 2005.

GOHN, Maria G. Teorias dos movimentos sociais: paradigmas clássicos e contemporâneos. São Paulo: Loyola, 1997.

Movimentos sociais e redes de mobilizações civis no Brasil contemporâneo. Petrópolis: Vozes, 2010.

GOLDMAN, Márcio. Políticas e subjetividades nos "novos movimentos culturais". Revista Ilha, v. 9, n. 1, p. 9-22, 2007.

KITTAY, Eva. Love's Labor. Essays on women, equality and dependency. Nova York: Routledge, 1998.

When Caring is Just and Justice is Caring. In: KITTAY, E.; FEDER, E. (Eds.). The Subjects of Care: feminist perspectives on dependency. Lanham, Md.: Rowman \& Littlefield, 2001.

The Ethics of Care, Dependence and Disability. Ratio Juris, v. 24, n. 1, 2011, p. 49-58.

LACERDA, Paula M. Mobilização social, política e administração pública no caso dos meninos emasculados de Altamira. Amazônica - Revista de Antropologia, v. 3, n. 2, p. 300-323, 2012.

MELLO, Anahí Guedes. Por uma abordagem antropológica da deficiência: pessoa, corpo e subjetividade. Trabalho de Conclusão de Curso, Universidade Federal de Santa Catarina, Florianópolis, 2009.

MELUCCI, Alberto. A invenção do presente: movimentos sociais nas sociedades complexas. Petrópolis: Vozes, 2001.

MUSSE, Luciana. Novos sujeitos de direito. Rio de Janeiro: Elsevier, 2008.

NUNES, Fernanda. Atuação política de grupos de pais de autistas no Rio de Janeiro: perspectivas para o campo da saúde. Dissertação (mestrado) - Universidade do Estado do Rio de Janeiro, 2014.

; ORTEGA, Francisco. Ativismo político de pais de autistas no Rio de 
Janeiro: reflexões sobre o "direito ao tratamento". Revista Saúde e Sociedade, v. 25, n. 1, no prelo.

OLIVER, Mike. The Politics of Disablement. Basingstoke: Macmillan, 1990.

ORGANIZAÇÃO DAS NAÇÕES UNIDAS (ONU). World Autism Awareness Day. Resolução Adotada por Assembleia Geral, em 18 de dezembro de 2007. Disponível em: <http://www.un.org/en/ga/search/view_doc.asp?symbol=A/RES/62/139>. Acesso em: 13/set./2013.

PAIVA JÚNIOR, Francisco. Autismo: não espere, aja logo. São Paulo: Mbooks, 2012.

SANTOS, Tiago M. Políticas e subjetividades: itinerários do ativismo soropositivo. Florianópolis. Dissertação (Mestrado) - Universidade Federal de Santa Catarina, 2005.

SASSAKI, Romeu. Deficiência mental ou intelectual? Doença ou transtorno mental? Atualizações semânticas na inclusão de pessoas. Revista Reação, São Paulo, 9, n. 43, p. 9-10, 2005.

Por falar em classificação de deficiências. Revista Brasileira de Tradução Visual, v. 12, n. 12, 2012.

SHOPLER, Eric; REICHLER, R. Parents as Cotherapists in the Treatment of Psychotic Children. Journal of Autism and Childhood Schizophrenia, n. 1, v. 1, p. 87-102, 1971.

SILVERMAN, Cloe. Understanding Autism: parents, doctors, and the history of a disorder. Princeton, NJ: Princeton UP, 2012.

VELHO, Gilberto. A utopia urbana: um estudo de antropologia social. Rio de Janeiro: Zahar, 1989.

VIANNA, Adriana; FARIAS, Juliana. A guerra das mães: dor e política em situações de violência institucional. Cadernos Pagu, v. 37, p. 79-116, 2011.

\section{autora Fernanda Nunes}

Doutoranda em Antropologia pelo Programa de Pós-graduação em Sociologia e Antropologia da UFRJ (PPGSA/ IFCS/UFRJ), mestre em Saúde Coletiva pelo Instituto de Medicina Social da UERJ, com concentração em Ciências Humanas e Saúde (2014), e graduada em Ciências Sociais pelo Centro de Pesquisa e Documentação de História Contemporânea do Brasil da FGV (2009).

Recebido em 01/04/2016

Aceito para publicação 17/01/2017 